\title{
Historia natural de la primoinfección por Herpes Virus 6
}

\section{Objetivo}

Estudiar la historia natural y manifestaciones clínicas de la primoinfección por Herpes Virus 6 (HHV6).

\section{Diseño}

Cohorte prospectiva* con base poblacional.

Lugar

Centros obstétricos en Seattle, EE.UU.

\section{Pacientes}

Recién nacidos entre 1997 a 2001, con un seguimiento hasta los 2 años de vida.

\section{Evaluación de los factores pronósticos}

Se evaluaron condiciones demográficas, y síntomas diarios.

\section{Medición de resultado principal}

Semanalmente se realizaba la toma de muestra de saliva de los chicos, en donde se realizaba la técnica de PCR (detecta DNA viral) para HHV6, y se definía infección a la positividad de PCR y su posterior persistencia. Se analizó la edad de primoinfección, síntomas asociados a la primoinfección y factores asociados a la adquisición de la misma, así como la comparación de niños infectados con los no infectados.

\section{Resultados}

Se incluyeron 277 niños, $46 \%$ mujeres, $80 \%$ de raza blanca. La mediana de seguimiento fue de 60 semanas (1-113). Del total, 130 tuvieron primoinfección, con una tasa de incidencia acumulativa del $40 \%$ hasta los 12 meses y del $77 \%$ (IC95\% 67 a 88 ) a los 24 meses. El pico de adquisición se encontró entre los 9 y 21 meses. Sólo mostraron asociación significativa con la infección el sexo femenino (OR 1,7; IC95\% 1,2 a 2,4) y tener un hermano mayor (OR 2,$1 ;$ IC $95 \% 1,4$ a 2,9). No hubo relación con la lactancia o la concurrencia a guarderías. De los primoinfectados, el 93\% presentó síntomas, el $38 \%$ visitó al médico y ninguno presentó convulsiones. En la tabla se observan los síntomas principales. La roséola fue el signo más específico pero se presentó en menos de un cuarto de los casos; la duración promedio de los síntomas fue mayor en la infección por HHV6 (9 días; IC95\% 4 a 15) que en otras enfermedades febriles de la infancia (3 días; IC95\% 2 a 7); $\mathrm{p}<0.001$. La fiebre se presentó más frecuentemente en los mayores de 6 meses ( $93 \%$ vs. $66 \% \mathrm{p}<0.004$ ).

Tabla. Incidencia de los síntomas y visitas al médico en los niños con primoinfección HHV6 vs los controles.

\begin{tabular}{|c|c|c|c|}
\hline Sintoma & HHV6 Positivo ( $(=80)$ & HHV6 Negativo (N=80) & p \\
\hline Algun síntoma & $94 \%(\mid C 9588-99)$ & $71 \%($ IC9561-81) & 0.004 \\
\hline Irritabilidad & $70 \%($ IC9560-80) & $46 \%($ IC95 $35-57)$ & 0.009 \\
\hline Rinorrea & $66 \%($ IC95 $56-77)$ & $46 \%$ (IC95 35-57) & 0.02 \\
\hline Fiebre & $58 \%($ IC95 $47-68)$ & $14 \%(\mid C 956-21)$ & $<0.001$ \\
\hline Rash & $31 \%($ IC95 $21-41)$ & $8 \%\left(\begin{array}{lll}\text { IC95 } & 2-13\end{array}\right)$ & 0.002 \\
\hline Diarrea & $26 \%(\mid$ C95 $17-36)$ & $11 \%($ IC95 $4-18)$ & 0.05 \\
\hline Roseola & $24 \%($ IC95 $14-33)$ & $3 \%($ IC95 $0-6)$ & 0.003 \\
\hline Convulsión & $0 \%($ IC95 $0-2)$ & $0 \%($ IC95 $0-2)$ & \\
\hline Visita al médico & $39 \%($ IC95 $28-49)$ & $19 \%$ (IC95 $10-27)$ & 0.009 \\
\hline
\end{tabular}

\section{Conclusión}

La adquisición del virus HHV6 es usualmente sintomática y frecuentemente necesita evaluación médica. La roseola es específica pero poco sensible, y lo más habitual es la fiebre y un cuadro de vías aéreas superiores. Las convulsiones febriles no son habituales.

\section{Comentario}

El HHV6 es conocido como el virus causante del exantema súbito o sexta enfermedad en menores de 2 años, pero hasta este trabajo no quedaba clara la contribución real de esta infección a la morbilidad infantil como las convulsiones febriles, con las cuales se creía asociada..$^{1-2}$

Los autores se plantearon evaluar la historia natural de esta enfermedad y su asociación con convulsiones febriles y para ello utilizaron un diseño de cohorte prospectivo*, de elección para este tipo de estudios, aunque existió una pérdida de seguimiento del $23 \%$ que no fue reportada, la cual es considerada significativa para la evaluación de la validez interna* del estudio.

De todas maneras, una de las fortalezas del trabajo es la continuidad en el seguimiento de los chicos durante los dos años, como por ejemplo la realización semanal de la prueba en la saliva y completar el cuestionario de los síntomas diariamente.

De acuerdo al resultado de este estudio podemos decir que la adquisición del virus HHV6 es usualmente sintomática (puede presentarse como fiebre prolongada e irritabilidad como únicos síntomas) y frecuentemente necesita evaluación médica. Esto probablemente sea debido a que la fiebre sin foco en los niños menores de 2 años es un signo de alarma para los padres, que los lleva a consultar al sistema de salud.

En relación a la forma de presentación, la roséola, signo considerado patognomónico de la infección es, como tantos otros signos patognomónicos, poco frecuente. Es decir, es muy específico* pero poco sensible* para detectar la enfemedad.

Las convulsiones febriles mostraron en estudios previos una relación estrecha con el $\mathrm{HHV}^{2}$, sin embargo este no fue el caso en este trabajo, en donde no hubo convulsiones febriles. Esto podría deberse a una falta de poder* para detectar tal asociación, ya que en el caso de síntomas poco frecuentes como es el caso de las convulsiones, se necesitaría una muestra más amplia para poder responder esta pregunta.

En relación a la vía de contagio, la convivencia con chicos mayores parece encontrarse asociada con la adquisición de la infección, aunque no se registró tal asociación en relación a otros ámbitos en donde los niños se encuentran en estrecho contacto, como las guarderías.

\section{Conclusiones del comentador}

En resumen, el HHV6 se presenta frecuentemente como un cuadro febril en menores de 2 años y es motivo de consulta frecuente al médico. Deberíamos tenerlo en cuenta sobre todo en niños que tienen hermanos mayores y no esperar la clásica roseola. Se necesitan más estudios para descartar definitivamente su asociación con las convulsiones febriles.

Dra. Ariana Cheng [ Unidad de Medicina Familiar y preventiva. Hospital Italiano de Buenos Aires. ]

Cheng, A. Primoinfección por Herpes Virus 6: Estudio poblacional prospectivo Evid. actual. práct. ambul. 2005;8:74. Comentado de: Zerr DM, Meier A, Selke SS y cols. A Population Based-Study of Primary Human Herpes virus 6 infection. N Engl J Med. 2005. 352:768-776. PMID 15728809

Referencias

1. Prober C. Sixth Disease and the Ubiquity of Human Herpesviruses. NEJM Feb 24, 2005; 352:753-755.

2. Hall CB, Long CE, Schnabel KC, et al. Human herpesvirus-6 infection in children: a prospective study of complications and reactivation. N Engl J Med 1994:331:432-438. 